tubuline libre correspond à l'extrémité $\mathrm{NH}_{2}$-terminale de la protéine et, d'autre part, à l'affínité qu'ont les unes pour les autres les molécules de tubuline, milite en faveur d'une interaction entre les sous-unités non polymérisées de tubuline et l'extrémité $\mathrm{NH}_{2}$-terminale de la chaîne protéique naissante, en cours de synthèse (figure 1, page 193). Une telle interaction pourrait modifier la conformation de l'ARN, le sensibilisant à l'action d'une ribonucléase. Également en faveur de ce mécanisme hypothétique est l'insensibilité du phénomène aux inhibiteurs de la synthèse protéique qui ne détruisent pas les polysomes (cycloheximide, par exemple). Un tel phénomène de contrôle de l'expression d'un gène par son produit est exceptionnel, l'un des rares autres exemples connus étant celui de l'antigène $T$ du virus SV-40 qui, entre autres effets, inhibe la transcription de son gène. Une autre grande originalité du système tubuline est la localisation dans la séquence codante du motif responsable de l'instabilité du messager en présence de sous-unités ou de dimères libres; dans la plupart des autres exemples connus de contrôle de la stabilité d'un messager, les motifs conférant cette propriété sont localisés dans l'extension 3' non codante des ARNm [exemples des messagers $c$-fos, $c$-myc, du messager du facteur de croissance CSF-1 (ou M$\mathrm{CSF}$ )] et la déstabilisation du messager nécessite une synthèse protéique active, probablement nécessaire à la production de l'agent «déstabilisant ».

A.K.

1. Gay DA, Yen T J, Lau JTY, Cleveland DW. Sequences that confer $\beta$ tubulin autoregulation through modulated mRNA stability resside within exon 1 of a $\beta$ tubulin mRNA. Cell $1987 ; 50: 671-9$.

2. Cleveland DW. The multitubulin hypothesis revisited : what have we learned? J Cell Biol 1987; 104 : 381-3.

3. Pachter JS, Yen TY, Cleveland DW. Autoregulation of tubulin expression is achieved through specific degradation of polysomal tubulin mRNAs. Cell 1987; $51: 283-92$

\title{
Réévaluation du risque des radiations
}

Les normes de protection actuellement en vigueur dans le monde reposent sur l'étude d'environ 90000 survivants des deux explosions atomiques qui eurent lieu à Nagasaki et à Hiroshima. La dose de radiations reçue par la population lors des explosions ne fut jamais déterminée avec précision; seules des tentatives de dosimétrie furent effectuées en 1965 par les Américains et les Japonais. Quelques années plus tard, on s'aperçut que les modélisations utilisées pour établir les normes de sécurité étaient basées sur des données inexactes. Il fallut, pour des raisons scientifiques et politiques, plus de dix ans pour en apporter la démonstration. C'est aujourd'hui chose faite et les conclusions sont fort inquiétantes: les normes en vigueur sous-estiment le risque de cancer après irradiation gamma, d'un facteur au moins égal à deux [1]. Cette sous-estimation résulte d'une analyse incorrecte de la composition des rayonnements émis par la bombe d'Hiroshima, surestimant la proportion des neutrons sur les rayons gamma. Les cancers survenant dans cette région furent attribués aux effets de ces neutrons que l'on sait être beaucoup plus cancérigènes que les rayons gamma. En réalité, il y avait très peu, voire pas de neutrons si l'on tient compte de la forte humidité qui régnait en ce lieu, les neutrons étant dans ces conditions fortement absorbés par l'air. Ainsi tous les cancers répertoriés dans cette zone doivent être imputés aux rayons gamma. D’autre part les modélisations actuelles montrent qu'un nombre important de survivants ont reçu des doses bien inférieures à celles précédemment estimées. A l'appui de ces nouvelles estimations des risques, il faut ajouter qu'au cours des onze dernières années, le nombre de décès parmi les survivants a dépassé de 100 à 300 le chiffre prévu. Dans l'ensemble, les gouvernements veulent attendre que soient confrontés et confirmés tous ces résultats avant de modifier, comme le souhaitent de nombreux scientifiques et organismes de contrôle, les normes de protection des travailleurs et du public exposés aux radiations environnementales et médicales; seule la Grande-Bretagne semble d'ores et déjà convaincue de la nécessité d'abaisser le seuil acceptable des radiations.

P.B.

1. Roberts L. Atomic bomb doses reassessed. Science 1987; $238: 1649-51$.

\section{BRĖVES}

Des souris transgéniques porteuses de lésions héréditaires du cristallin. Une «brève » récente $\left(\mathrm{m} / \mathrm{s} n^{\circ} 9\right.$, vol. 3, p. 557) annonçait le premier succès de destruction élective (ici du pancréas) chez des souris transgéniques et laissait prévoir des développements rapides de la methode. C'est encore un ADN codant pour la toxine diphtérique qui a été utilisé par une équipe canadienne et américaine, mais il a été placé cette fois sous le contrôle du promoteur de la $\gamma$ cristalline; introduite dans des œufs fécondés, cette construction provoque chez les souris transgéniques une microphtalmie transmissible sur plusieurs générations, avec des lésions du cristallin de gravité variable, sans aucune anomalie extra-oculaire. Les auteurs appellent cette méthode «ablation génétique ». [Breitman ML, et al. Science 1987 ; 238 : 1563-5.] 